\title{
Regenerative ability of grape cuttings under the influence of yeast suspension treatment
}

\author{
Pyotr Radchevsky*, Vladimir Kutakov, Oleg Smolich, and Ivan Chursin \\ Federal State Budgetary Educational Institution of Higher Education"Kuban State Agrarian \\ University named after I. T. Trubilin", str. Kalinina, 13, Krasnodar, 350044, Russia
}

\begin{abstract}
The paper presents the growing experiment results on activating the regenerative ability of Moldova table variety grape cuttings by processing pressed baking yeast suspension. The present circumstance became the basis for conducting special studies to check cutting response to the treatment with baking yeast suspension, with the identification of drug optimal concentration. In spring, the two-eyed cuttings were completely soaked for 24 hours in water, and then they were placed with the basal ends in yeast suspension at various concentrations for the same time. Moreover, these yeast suspension concentrations were tested both in pure form and in combination with $3 \%$ sucrose. As a result of the conducted studies, it was revealed that pressed baking yeast suspension at certain concentration can have an activating effect on regenerative ability of grape cuttings. The use of yeast suspension together with sucrose solution increases their physiological activity. It was found that cuttings basal end soaking in yeast suspension at concentrations of 10-20 g/l, together with sucrose, contributed to rooting increased by $20-30 \%$, the proportion of cuttings with three roots or more - by $22.5-30.0 \%$, the number of roots by $13.5-16.2 \%$. The best option was with a yeast suspension concentration of $20 \mathrm{~g} / \mathrm{l}$.
\end{abstract}

\section{Introduction}

To stimulate the root-forming ability of cuttings, farmers and industrial winegrowers engaged in the production of planting material use both synthetic and natural growth regulators [1-5]. In addition, there is an increasing interest in the use of bacteria in many viticulture processes [6-7]. Work is underway to study the dynamics of the growth of thin roots in grapes [8]. The influence of mineral nutrients, carbohydrates, trace elements, strigolactones and brassinosteroids on the development of vines and fruit crops is studied [9-14]. However, there is practically no data in scientific literature on the effectiveness of natural growth regulators use and there is only general information about technological parameters of their application, including yeast. This circumstance was the basis for our special research on this issue.

Since there was an interest in the use of yeast not only in winemaking [15], but also in viticulture, we conducted preliminary studies to investigate the effect of grape cuttings treatment with yeast suspension at concentrations of $25,50,75$ and $100 \mathrm{~g} / \mathrm{l}$ on their

*Corresponding author: radchevskii@,rambler.ru 
regenerative properties. The lowest concentration of the drug was the most effective. After receiving the initial results, the research program was concretized, as well as deepened and expanded. At the same time, it was decided to test the new concentrations of yeast suspension both in pure form and together with a sucrose solution.

The aim of the research is to study the response of grape cuttings to treatment with yeast suspension of various concentrations, both in pure form and together with sucrose, in order to establish the optimal one that has the maximum effect on their regenerative ability.

\section{Objects and methods}

Objects of the research: two-eyed cuttings of table grapes of the Moldova variety, treated with a suspension of baking yeast.

The scheme of the experiment: soaking in water (control); yeast $5 \mathrm{~g} / \mathrm{l}$; yeast $10 \mathrm{~g} / \mathrm{l}$; yeast $15 \mathrm{~g} / \mathrm{l}$; yeast $20 \mathrm{~g} / \mathrm{l}$; yeast $5 \mathrm{~g} / \mathrm{l}+$ sucrose $30 \mathrm{~g} / \mathrm{l}$; yeast $10 \mathrm{~g} / \mathrm{l}$ + sucrose $30 \mathrm{~g} / \mathrm{l}$; yeast $15 \mathrm{~g} / \mathrm{l}$ + sucrose $30 \mathrm{~g} / \mathrm{l}$; yeast $20 \mathrm{~g} / \mathrm{l}+$ sucrose $30 \mathrm{~g} / \mathrm{l}$.

In the spring, the cuttings of the Moldova variety were cut to the required length, tied into bundles of 40 pieces and after 24-hour soaking in water, the lower ends were soaked for 24 hours in a suspension in accordance with the scheme of the experiment. After treatment, the cuttings have been germinated in plastic containers with water. The water layer was maintained at the level of $2.5-3 \mathrm{~cm}$ during the entire experiment.

The study of regenerative properties of cuttings was carried out according to the methods developed and repeatedly tested at the department of viticulture of Kuban State Agrarian University [1].

\section{Results and discussion}

In most variants, the proportion of cuttings with blooming eyes was in the range of 90.0-97.5 $\%$, which indicates a high viability of eyes (Table 1 ). The value of the indicator in experimental variants with yeast suspension, with rare exceptions, was at the control level.

The addition of sucrose to the yeast suspension, in three variants, led to a decrease in the indicator. A particularly significant decrease in the proportion of cuttings with blooming eyes was observed in variants with a yeast suspension concentration of 5 and $20 \mathrm{~g} / \mathrm{l}$.

Table 1. Indicators of the shoot-forming ability of cuttings of grapes of the Moldova variety under the influence of treatment with a suspension of yeast of various concentrations

\begin{tabular}{|l|c|c|c|}
\hline \multicolumn{1}{|c|}{ Type } & $\begin{array}{c}\text { Proportion of } \\
\text { cuttings with } \\
\text { blooming eyes, \% }\end{array}$ & $\begin{array}{c}\text { Duration of the } \\
\text { eyes' opening, } \\
\text { days }\end{array}$ & $\begin{array}{c}\text { Length of } \\
\text { shoots, cm }\end{array}$ \\
\hline Soaking in water (control) & 95,0 & 8 & 9,6 \\
\hline Yeast $5 \mathrm{~g} / 1$ & 97,5 & 8 & 6,0 \\
\hline Yeast $10 \mathrm{~g} / 1$ & 97,5 & 8 & 10,5 \\
\hline Yeast $15 \mathrm{~g} / 1$ & 72,5 & 8 & 9,8 \\
\hline Yeast $20 \mathrm{~g} / 1$ & 95,0 & 8 & 9,8 \\
\hline Yeast $5 \mathrm{~g} / 1+$ sucrose $30 \mathrm{~g} / 1$ & 65,0 & 8 & 11,8 \\
\hline Yeast $10 \mathrm{~g} / 1+$ sucrose $30 \mathrm{~g} / 1$ & 90,0 & 8 & 10,8 \\
\hline Yeast $15 \mathrm{~g} / 1+$ sucrose $30 \mathrm{~g} / 1$ & 92,5 & 13 & 13,6 \\
\hline Yeast $20 \mathrm{~g} / 1+$ sucrose $30 \mathrm{~g} / 1$ & 72,5 & 11 & 15,2 \\
\hline LSD $_{01}$ & 8,7 & 1,8 & 1,1 \\
\hline
\end{tabular}


The eyes of cuttings in most variants bloomed in an average of 8 days. Only in variants where a suspension of yeast in an increased concentration was used for cuttings treatment, and moreover, together with sucrose, the eyes opened 5 and 3 days later, respectively. The difference between the control and these variants turned out to be reliable.

A significant decrease in the length of shoots was observed in the variant with a yeast suspension concentration of $5 \mathrm{~g} / \mathrm{l}$. The value of this indicator was at the control level in the remaining three experimental variants with a yeast suspension at a concentration of 10,15 and $20 \mathrm{~g} / \mathrm{l}$.

The addition of sucrose to the yeast suspension led to a significant increase in the length of shoots. This is another confirmation of the fact that sugars in cuttings perform the role of an energy substance that positively affects all growth processes. At the same time, there was a tendency to increase the length of shoots as the concentration of yeast suspension increased, although the concentration of sucrose was the same in all variants.

Soaking the cuttings in a yeast suspension of the lowest concentrations, that is, 5 and 10 $\mathrm{g} / \mathrm{l}$, led to an increase in rooting by 19.5 and $10.0 \%$, although a significant difference at $\mathrm{LSD}_{01}=11.1 \%$ was obtained only in the first case (Table 2 ).

Rooting was at the control level at concentrations of 15 and $20 \mathrm{~g} / \mathrm{l}$. At the control level there was also the value of the indicator in the variant where sucrose was added to the yeast suspension with a concentration of $5 \mathrm{~g} / \mathrm{l}$.

The addition of sucrose to the yeast suspension at concentrations of 10,15 and $20 \mathrm{~g} / 1$ led to a significant increase in rooting ability - compared with the control, the excess was 17.0, 15.0 and $22.0 \%$.

Thus, if the lowest concentrations of the drug provided the greatest rooting effect when using a pure yeast suspension, then the highest concentrations were more effective when adding sucrose to the suspension.

Treatment of cuttings with yeast suspension and sucrose had a different effect on the rate of root formation. Thus, in the variants with pure yeast distribution at a concentration of 10 $\mathrm{g} / \mathrm{l}$, an increase was observed in the length of the pre-root period, and a decrease was observed at $20 \mathrm{~g} / \mathrm{l}$. At concentrations of 5 and $15 \mathrm{~g} / \mathrm{l}$, the first roots appeared at about the same time as in the control.

Table 2. Indicators of the root-forming ability of cuttings of grapes of the Moldova variety under the influence of treatment with a suspension of yeast of various concentrations

\begin{tabular}{|c|c|c|c|c|}
\hline Type & $\begin{array}{c}\text { Rooting, } \\
\%\end{array}$ & $\begin{array}{c}\text { Length of } \\
\text { pre-rooting } \\
\text { period, days }\end{array}$ & $\begin{array}{c}\text { Share of } \\
\text { cuttings with } \\
\text { three roots } \\
\text { and more, } \\
\%\end{array}$ & $\begin{array}{l}\text { Number of } \\
\text { roots per } \\
\text { cutting, pes }\end{array}$ \\
\hline Soaking in water (control) & 52,5 & 19,2 & 40,0 & 3,7 \\
\hline Yeast $5 \mathrm{~g} / \mathrm{l}$ & 72,5 & 18,8 & 50,0 & 4,8 \\
\hline Yeast $10 \mathrm{~g} / 1$ & 70,0 & 23,0 & 60,0 & 4,1 \\
\hline Yeast $15 \mathrm{~g} / 1$ & 45,0 & 19,2 & 37,5 & 4,0 \\
\hline Yeast $20 \mathrm{~g} / 1$ & 40,0 & 17,0 & 25,0 & 2,7 \\
\hline Yeast $5 \mathrm{~g} / 1+$ sucrose $3,0 \mathrm{~g} / 1$ & 50,0 & 16,6 & 45,0 & 4,8 \\
\hline Yeast $10 \mathrm{~g} / 1+$ sucrose $3,0 \mathrm{~g} / 1$ & 77,5 & 19,0 & 67,5 & 3,6 \\
\hline Yeast $15 \mathrm{~g} / 1+$ sucrose $3,0 \mathrm{~g} / 1$ & 72,5 & 21,0 & 62,5 & 4,2 \\
\hline Yeast $20 \mathrm{~g} / 1+$ sucrose $3,0 \mathrm{~g} / 1$ & 82,5 & 17,0 & 70,0 & 4,3 \\
\hline $\mathrm{LSD}_{01}$ & 11,1 & 2,1 & 11,6 & 0,54 \\
\hline
\end{tabular}

In the variants with combined use of yeast suspension and sucrose, the acceleration of root formation was revealed in the variants with drug concentrations of 5 and $20 \mathrm{~g} / \mathrm{l}$, the 
slowdown was $15 \mathrm{~g} / \mathrm{l}$. In the variant with a concentration of $10 \mathrm{~g} / \mathrm{l}$, the roots appeared simultaneously with the control.

As for one of the most important physiological and economic signs of the root-forming ability of cuttings - the yield of cuttings with three roots or more, among the variants with a pure yeast suspension, only in the variant with a drug concentration of $10 \mathrm{~g} / \mathrm{l}$, it significantly exceeded the control.

With the combined use of a suspension of yeast and sucrose, a significant excess of the proportion of cuttings with three roots or more was observed in the same three variants, where the greatest rooting ability was noted, that is, with a yeast concentration of 10,15 and $20 \mathrm{~g} / \mathrm{l}$. The excess value ranged from 22.5-30.0\%, with the highest value in the variant with the maximum concentration of yeast.

In most variants, the average number of roots per one stalk was approximately the same as in the control and ranged from 3.6-4.2 pcs. A significant excess of this indicator was detected only in the variants with a pure yeast suspension at a concentration of $5 \mathrm{~g} / \mathrm{l}$ and in the variants of joint use of a yeast suspension with sucrose at a concentration of the first component of 5 and $20 \mathrm{~g} / 1$.

In the variants with a pure yeast suspension, there was a decrease in the average number of roots from 4.8 to 2.7 pieces, with an increase in the concentration of the drug from $5 \mathrm{~g} / 1$ to $20 \mathrm{~g} / \mathrm{l}$.

\section{Conclusion}

It was found that the treatment of cuttings of grapes of the Moldova variety with a suspension of yeast in concentrations of 15 and $10 \mathrm{~g} / \mathrm{l}$ has a stimulating effect on intensity of eyes' blossoming. There was a delay in the opening of eyes at the highest concentration of yeast suspension $(20 \mathrm{~g} / \mathrm{l})$.

An increase in the rooting of cuttings was noted at the concentration of yeast suspension of 5 and $10 \mathrm{~g} / \mathrm{l}$ - by 20.0 and $17.5 \%$, respectively. When sucrose was added, the best results were obtained at concentrations of 10 and $20 \mathrm{~g} / \mathrm{l}$ - the excess of the indicator over the control was 25 and $30 \%$, respectively.

It was found that in the variants with the addition of sucrose at a yeast concentration of 5 and $20 \mathrm{~g} / \mathrm{l}$, root formation accelerates, and it slows down in the variant with a concentration of $15 \mathrm{~g} / \mathrm{l}$.

The addition of sucrose to the suspension at a yeast concentration of 10,15 and $20 \mathrm{~g} / \mathrm{l}$ increases the yield of cuttings with three roots or more by $25.0-40.0 \%$ compared to the control.

Thus, a suspension of pressed baking yeast, together with a sucrose solution at a concentration of the first component of $10-20 \mathrm{~g} / \mathrm{l}$, is an effective stimulant of the root-forming ability of grape cuttings, which can positively affect the yield and quality of seedlings.

\section{References}

1. A.P. Ovcharova, P.P. Radchevsky, E.A. Kaygorodova, N.E. Kosyanok, M.A. Pudovkina, Proceedings of Kuban State Agrarian University, 76, 135-141 (2019) https://doi.org/10.21515/1999-1703-76-135-141

2. M.A. Nikolsky, M.I. Pankin, Fruit Growing and Viticulture of South Russia, 54 (6), 2232 (2018) https://doi.org/10.30679/2219-5335-2018-6-54-22-32

3. O.L. Seget, I.A. Avdeenko, G. Aleynikova, G. Malih, BIO Web Conf., 25, 05010 (2020) https://doi.org/10.1051/bioconf/20202505010 
4. I. Daskalakis, K. Biniari, D. Bouza, M. Stavrakaki, Sci. Hortic., 227, 79-84 (2018) https://doi.org/10.1016/j.scienta.2017.09.024

5. Q. Zhou, B. Gao, W-F. Li, J. Mao, Sh.-J. Yang, W. Li, Z-H. Ma, X. Zhao, B-H. Chen, Sci. Hortic, 264, 109186 (2020) https://doi.org/10.1016/j.scienta.2020.109186

6. M. V. Salomon, P. Piccoli, I. F. Pinter, W. A.Stirk, M. Kulkarni, J. van Staden, R. Bottini, Plant Physiol. Biochem., 120, $\quad 1-9 \quad$ (2017) https://doi.org/10.1016/j.plaphy.2017.09.013

7. A. Sabir, Sci. Hortic., 164, 24-29 (2013) https://doi.org/10.1016/j.scienta.2013.08.035

8. K.P. Mahmud, J.P. Smith, S.Y. Rogiers, Sh. Nielsen, Y. Guisard, B.P. Holzapfel, Sci. Hortic., 250, 138-147 (2019) https://doi.org/10.1016/j.scienta.2019.02.035

9. A.Tsafouros, A. Frantzeskaki, A. Assimakopoulou, P.A. Roussos, Sci. Hortic., 253, 227 240 (2019) https://doi.org/10.1016/j.scienta.2019.04.049

10. C. Castro, A. Carvalho, I. Pavia, E. Bacelar, J. Lima-Brito, Plant Phys. Biochem., 166, 887-901 (2021) https://doi.org/10.1016/j.plaphy.2021.07.003

11. B. Ali, Sci. Hortic., 225, 15-21 (2017) https://doi.org/10.1016/j.scienta.2017.06.051

12. Zh. Min, Z. Li, L. Chen, Y. Zhang, M. Liu, X. Yan, Y. Fang, Sci. Hortic., 283, 109936 (2021) https://doi.org/10.1016/j.scienta.2021.109936

13. Kh. S. Siddiqi, A. Husen, Applied Soil Ecology, 120, 247-253 (2017) https://doi.org/10.1016/j.apsoil.2017.08.020

14. C. Castro, A. Carvalho, I. Pavia, E. Bacelar, J. Lima-Brito, Sci. Hortic., 288, 110386 (2021) https://doi.org/10.1016/j.scienta.2021.110386

15. A.R. Borneman, S.A. Schmidt, I.S. Pretorius, Trends Genet., 29, 263-271 (2013) https://doi.org/10.1016/j.tig.2012.10.014 